\title{
A realização da sequência narrativa no cordel
}

\author{
The narrative's sequence realization in cordel
}

\section{La realización de la secuencia narrativa en el cordel}

\author{
Luana Aparecida da Silva ${ }^{1}$ \\ Elvira Lopes Nascimento ${ }^{2}$
}

\begin{abstract}
RESUMO: O presente artigo tem por objetivo apresentar uma análise da realização da sequência narrativa no cordel As minas de Minas, do poeta Chico Salles, publicado em 2008. Para tanto, utilizamos como cunho teórico-metodológico principal os preceitos de Adam (1992) e de Bronckart (2003). Para realizarmos este estudo, inicialmente efetuamos uma reflexão sobre as sequências prototípicas, em seguida, apresentamos o protótipo narrativo e por fim analisamos seu encadeamento e função no texto. A análise desses construtos teóricos nos permitiu constatar que a sequência narrativa contribui para dar forma ao cordel, e todas as suas macroproposições são usadas na constituição das personagens e no desenvolvimento da narrativa.
\end{abstract}

PALAVRAS-CHAVE: Sequência narrativa. Organização sequencial. Cordel.

ABSTRACT: The following article has as the main objective to present an analysis on the narrative sequence on the Cordel "As minas de minas", from the poet Chico Salles, published in 2008. For the study we use as theoretical-methodological basis the preceptions of Adam (1992) and Bronckart (2003). For the study practices, initially we had a reflection on the prototype sentences, and as follows, we shared the narrative prototype. Finally, we analyzed their physical binding and its function on the text. The theoretical construct analysis allowed us to state that the narrative sequence helped shape the Cordel, and all its macropositions are used on the character development and in narrative development.

KEYWORDS: Narrative sequence. Sequential organization. Cordel.

RESUMEN: El presente artículo tiene por objetivo presentar un análisis de la realización de la secuencia narrativa en el cordel Las minas de Minas, del poeta Chico Salles, publicado en 2008. Para ello, utilizamos como base teórica-metodológica principal los preceptos de Adam (1992) y de Bronckart (2003). Para realizar este estudio, inicialmente efectuamos una reflexión sobre las secuencias prototípicas, a continuación, presentamos el prototipo narrativo y por fin analizamos su encadenamiento y función en el texto. El

\footnotetext{
${ }^{1}$ Mestranda do PPGEL- Programa de Pós-Graduação em Estudos da Linguagem da Universidade Estadual de Londrina - UEL. lu_apad@hotmail.com.

2 Docente associada da Universidade Estadual de Londrina, E-mail: elopes@sercomtel.com.br.
} 
análisis de estos constructos teóricos nos permitió constatar que la secuencia narrativa contribuye a dar forma al cordel, y todas sus macroproposiciones son usadas en la constitución de los personajes y en el desarrollo de la narrativa.

PALABRAS CLAVE: Secuencia narrativa. Organización secuencial. Cordel.

\section{Introdução}

O texto é um todo coerente com início, meio e fim, organizado por uma arquitetura interna que compreende três níveis superpostos: a infra-estrutura geral do texto, responsável pela capacidade de ação; os mecanismos de textualização, responsáveis pela capacidade discursiva; e os mecanismos enunciativos responsáveis pela capacidade linguístico-discursiva.

Para o ISD a infra-estrutura geral do texto compõe o nível mais profundo do folhado textual, constituída pelo plano mais geral do texto, pelos tipos de discurso, pelas sequências e as outras de planificação que nele estão presentes. Os mecanismos de textualização funcionam no nível intermediário do texto e estabelecem séries isotópicas que contribuem para a coerência temática do texto. Já os mecanismos enunciativos constituem o nível mais superficial do texto, contribuindo para a manutenção da coerência pragmática. Interessa-nos, aqui, discutir a infra-estrutura geral do texto, que se caracteriza também por outra dimensão, que é a da organização sequencial do conteúdo temático.

As sequências são como modos de planificação da linguagem que se desenvolvem no interior do texto, consideradas produtos de uma reorganização do conhecimento disponível na memória do agente-produtor que será tencionado. Os textos podem ser constituídos por um número $n$ de sequências, expressas de forma completa ou elíptica que permitem abordar a heterogeneidade composicional em termos hierárquicos gerais. A sequência pode ser entendida como uma rede nacional hierárquica, relativamente autônoma, integrada e organizada em macroproposições, que por sua vez, combinam proposições. Isso significar dizer que as proposições são "os componentes de uma unidade superior, a macroproposição, ela mesma unidade constituinte da 
sequência, ela mesma unidade constituinte do texto" (ADAM, 1991, p. 12). ${ }^{3}$ No presente artigo, busca-se observar a teoria de J. M. Adam acerca das sequências prototípicas, em especial a narrativa, de modo a analisarmos o seu encadeamento e sua função no cordel As minas de Minas, do poeta nordestino Chico Salles.

Para chegarmos à nossa proposta sobre a organização sequencial do cordel, efetuaremos inicialmente uma reflexão sobre a teoria da sequencialidade, procurando entender alguns aspectos, como a organização dos conteúdos do texto. A partir dessa discussão inicial, apresentaremos o que se pode considerar como esquema prototípico da sequência narrativa para, em seguida, verificar como o cordel é estruturado nessa forma de sequência.

Para desenvolver esse estudo, adotamos como referencial teórico a proposta da organização sequencial da textualidade de Adam (1992) e o interacionismo sociodiscursivo de Bronckart (2003). Adam em sua obra Les textes: types et prototypes (1992), atribui um papel determinante às sequências como mecanismo de organização da textualidade. Já Bronckart ${ }^{4}$ ao retomar a teoria das sequências, atribui às mesmas uma importância relativa, uma vez que estas compõem, mas não determinam a infraestrutura de um texto. A teoria desse autor será pertinente para complementar nossa leitura, possibilitando uma nova perspectiva e um contraponto em nossa análise.

\section{Sequências prototípicas}

Conforme destaca Silva (2007), a noção de sequência proposta por Adam, parte do princípio de que a unidade texto é muito complexa e heterogênea para apresentar regularidades linguísticas observáveis e codificáveis o que impossibilita uma definição estrita. A respeito do texto, Adam (1999) conclui que:

\footnotetext{
${ }^{3}$ Les composants d'une unité supérieure, le macroproposal, lui-même l'unité constitutive de la séquence, elle-même constituant le texte. (Tradução nossa)

${ }^{4}$ Segundo Bronckart (2003), as sequências estão a serviço dos tipos de discurso e em seu interior é que podem ser observadas. Assim, apresentam um caráter dialógico, já que são instrumentos a serviço da interação verbal.
} 
O texto é, portanto, por definição um objeto, em tensões entre as regularidades interdiscursivas de um gênero e as variações inerentes à atividade enunciativa de sujeitos engajados em uma interação verbal sempre historicamente singular. 0 gênero é somente o horizonte do texto, mas é bem mais que isso para o enunciador e para o enunciatário (apud SILVA, 2007, p. 22).

Diante da complexa classificação dos planos de texto e da heterogeneidade textual, o autor propôs que os fatos regulares, como narração, explicação, argumentação, descrição e diálogo, fossem situados em um nível sequencial. Para esse autor, os casos da heterogeneidade discursiva poderão ser contemplados apenas pela abordagem sequencial, uma vez que as sequências são "[...] formas específicas de organização dos conteúdos de um texto, [...] sendo a sua ocorrência e a sua combinação um dos elementos caracterizadores de um determinado gênero" (MACHADO, 1996, p. 136).

Bronckart (2003), ao observar a perspectiva teórica de Adam, chama atenção para o fato de que os tipos de discurso constituem os elementos fundamentais da infraestrutura geral de textos, a qual também se caracteriza pela dimensão da organização sequencial ou linear do conteúdo temático. 0 autor pontua que as sequências textuais compõem a infraestrutura de um texto, mas não a determinam e considera que as sequências estão inseridas nas formas de planificação local e que se encontram a serviço dos tipos de discurso. Sobre a concepção de sequência de Adam, o autor ainda afirma que:

Para esse autor, as sequências são unidades estruturais relativamente autônomas, que interagem e organizam macroproposições, que, por sua vez, combinam diversas proposições, podendo a organização linear do texto ser concebida como o produto da combinação e da articulação de diferentes tipos de sequências (BRONCKART, 2003, p. 218).

Nesse sentido, as sequências constituem protótipos, isto é, modelos abstratos dos quais os produtores e receptores disporiam, e passiveis de definição, ao mesmo tempo, pela estrutura das macroproposições que comportam e pelas modalidades de articulação dessas macroproposições. Entretanto, em linha com a perspectiva sociointeracionista, esses protótipos são apenas construtos teóricos, não procedem de uma competência textual 
biologicamente fundada, mas de uma experiência do intertexto, em suas dimensões práticas e históricas, podendo modificar-se permanentemente.

Diante dos pressupostos de Bronckart, percebemos que as sequências são frutos de um processo de reestruturação de um conteúdo temático já organizado na memória do agente produtor do texto na forma de macroestruturas. Essas macroestruturas, por sua vez, devem ser organizadas linearmente para formar um todo coerente que vai expressar o efeito de sentido que esse agente produtor pretende provocar no seu interlocutor. Dessa forma, "o empréstimo de um protótipo de sequência, disponível no intertexto, resulta, portanto, de uma decisão do agente-produtor, orientada por suas representações sobre os destinatários e sobre o fim que persegue" (BRONCKART, 2003, p. 234).

Para caracterizar as sequências prototípicas, Adam (1992) define cinco tipos de sequências: a narrativa, a descritiva, a argumentativa, a explicativa e a dialogal, sendo que estas podem ser combinadas em um texto, em várias modalidades, para que ocorra a heterogeneidade composicional da maioria dos textos. Bronckart (2003) adere às cinco sequências propostas por Adam, acrescentando à sua classificação a sequência injuntiva e estabelecendo para cada uma delas um estatuto dialógico, uma vez que são instrumentos a serviço da interação verbal. Assim, na sequência narrativa, a intenção é criar uma tensão; na sequência explicativa, resolver um problema; na sequência argumentativa, convencer; na sequência descritiva, fazer ver; na sequência dialogal, regular a interação; e, na sequência injuntiva, fazer agir.

\section{A sequência narrativa}

Essa sequência tem sido objeto de estudo constante desde a Poética de Aristóteles, e mais recentemente, pela escola francesa de narratologia, pela sociolinguística americana, bem como pela psicologia cognitiva. Independente da perspectiva de análise de cada vertente teórica, algo se mantém, pois só pode ser entendida como sequência narrativa se a organização textual é sustentada 
por um processo de intriga ${ }^{5}$, envolvendo personagens implicados em acontecimentos organizados no eixo do sucessivo.

A sequência narrativa refere-se à apresentação de fatos reais ou imaginários, cujos fatos podem ser ações ou eventos. "A ação se caracteriza pela presença de um agente [...] que prova ou tenta evitar uma mudança. $O$ evento acontece sob o efeito de causas, sem intervenção intencional de um agente" (ADAM, 2011, p. 225). Além disso, ela se apresenta sob diferentes formas de construção narrativa, as quais dependem de seu grau de narrativização. Uma narrativa tem baixo grau de narrativização quando apresenta somente uma simples enumeração de ações e alto grau de narrativização quando apresenta uma estrutura constituída por todas as macroproposições narrativas. Dessa forma, quando uma narrativa é sustentada por um processo de intriga, apresenta a sequência narrativa em seu alto grau de narrativização. Esse processo consiste na seleção e organização dos acontecimentos para formar um todo completo, com início, meio e fim, em que "à ordem cronológica dos acontecimentos se sobrepõe uma ordem interpretativa, que fornece causas e/ou razões aos diversos encadeamentos constitutivos da história" (BRONCKART, 2003, p. 220). A partir de um estado equilibrado, cria-se uma tensão, que desencadeia uma ou várias transformações, para isso são necessários seis constituintes, que reunidos, formam uma narrativa.

Segundo Adam (1992), a sequência narrativa se caracteriza em:

- Sucessão de eventos, que consiste na delimitação de evento em uma ordem temporal, ou seja, há um critério de temporalidade que envolve as narrativas, sendo que esta temporalidade deve ser dominada por uma tensão;

- Unidade temática, que destaca um sujeito principal, o qual desencadeará toda a ação narrada, mas o ator por si só não garante a

\footnotetext{
${ }^{5}$ De acordo com Adam (1992), não se pode falar em sequência narrativa se não houver seu elemento essencial, a intriga.
} 
unidade de ação, pois é necessária a relação com os outros componentes que caracterizam este sujeito;

- Predicados transformados, que consiste na transformação das características do personagem principal. A situação inicial em que o sujeito se encontra sofre mudança e se estabelece uma nova situação;

- Processo, que diz respeito à integração dos elementos da narrativa na unidade de uma mesma ação. A narrativa deve apresentar um início, um meio e um fim, pois para que haja narrativa, é preciso que os predicados transformados aconteçam no curso do processo.

- Intriga, que sustenta os fatos e pode fazer com que o narrador mude a ordem do processo, passando de uma simples sequência linear e temporal a uma lógica singular da narrativa;

- Avaliação final explícita ou implícita se refere à reflexão ou julgamento sobre o fato narrado.

Assim, deduzimos que o esquema protótipico da sequência narrativa constitui-se de macroproposições, que perfazem a situação inicial (Pn1), a complicação (Pn2), as ações (Pn3), a resolução $(P n 4)$ e a situaçã̃o final $(P n 5)^{6}$, e que estão fundamentadas nos seis elementos apresentados. $O$ autor afirma ainda que as macroproposições são meios de desenrolar a narrativa e que podem decorrer de uma simetria e de uma dinâmica, uma vez que "Pn1 é dinamizada por $\mathrm{Pn} 2$ e conduz a um estado transitório $\mathrm{Pn3}$, que se interrompe, ele próprio, sob o efeito de Pn4, que leva ao final Pn5" (ADAM, 2011, p. 228). Assim, cada Pn é responsável por um segmento na narrativa, tal como demonstrado por Nascimento, $2018^{7}$.

\footnotetext{
${ }^{6}$ A terminologia utilizada por Adam (1992), em relação ao processo de intriga, será diferente em obras mais recentes.

${ }^{7}$ Anotações de aula no PPGEL, 2018.
} 
Figura 1 - Protótipo da sequência narrativa

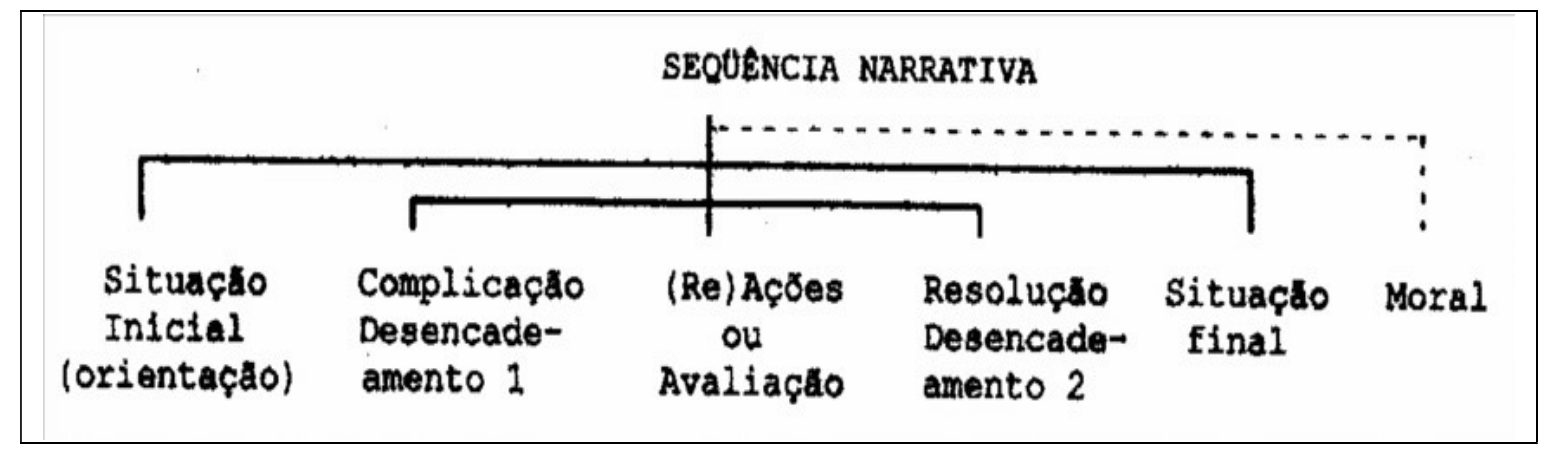

Fonte: Nascimento (2018) com base em Adam (1992).

O esquema representado pela autora se baseia no modelo do protótipo da sequência narrativa proposta por Adam e as fases que o compõem estão fundamentadas nos seis elementos apresentados pelo autor. Múltiplos modelos de sequência narrativa foram propostos, e o modelo mais comum é ancorado em três fases: situação inicial (início), transformação (meio) e situação final (fim). A partir dos estudos de Labov e Waletzky (1967), surgiu um modelo padrão, constituído de cinco fases para uma sequência narrativa:

- A fase de situação inicial, em que um estado de coisas é apresentado, estado esse que pode ser considerado equilibrado, mas que deverá ser tencionado;

- A fase da complicação, na qual introduz uma perturbação e cria-se uma tensão;

- A fase de ações, que reúne os acontecimentos originados pela perturbação;

- A fase de resolução, que introduz os acontecimentos que levam a uma redução da tensão;

- A fase da situação final, na qual um novo estado de equilíbrio é apresentado a partir da resolução; 
Além das cinco fases principais há também duas fases facultativas, sendo sua posição na sequência menos restrita, dependedo do posicionamento do narrador em relação à história narrada:

- A fase de avaliação, em que se propõe um comentário relativo ao desenrolar da história;

- A fase de moral, em que se explicita a significação global atribuída à história.

O protótipo narrativo de Adam compreende a maioria dessas fases, transformando as fases secundárias em apenas uma: a Moral ${ }^{8}$. As demais fases sofreram algumas alterações, no entanto conservaram sua ideias principais.

\section{Análise da sequência narrativa no cordel}

A seguir, apresentamos o cordel As minas de Minas, bem como as macroproposições narrativas identificadas. A análise a seguir foi estabelecida conforme a concepção prototípica de sequência narrativa proposta por Adam (1992) e retomada por Bronckart (2003).

\footnotetext{
${ }^{8}$ Utilizamos em nossa análise a macroproposição Moral $(\operatorname{Pn} \Omega)$ para marcar a avaliação explícita e/ou implícita.
} 
Quadro 1 - Nome do quadro

\begin{tabular}{|c|c|}
\hline Macroproposição & Ocorrência no cordel \\
\hline $\begin{array}{lr}\text { Situação } & \text { inicial } \\
\text { orientação }(P n 1)\end{array}$ & $\begin{array}{l}\text { Eu vou contar desta vez/ Um caso bem diferente/ Passado aqui no } \\
\text { Brasil/ De maneira comovente/ Tá escrito nos anais/ Foi lá em Minas } \\
\text { Gerais/ Este fato aqui presente. } \\
\text { Elas eram cinco minas/ Cinco meninas mineiras/ Todas da mesma } \\
\text { escola/ Também das mesmas ladeiras/ Moravam na mesma cidade/ E } \\
\text { tinham a mesma idade/ Mesmos gestos e maneiras. } \\
\text { Cidade de Montes Claros/ Lá pelo norte de Minas/ Em meados de } \\
\text { sessenta/ No tempo das brilhantinas/ De mais um ano dourado/ Ficou } \\
\text { assim registrado/ O caso dessas meninas. } \\
\text { Eram cinco coleguinhas / Terceiro ano primário/ Estudavam na escola/ } \\
\text { Da igreja do Rosário/ Na faixa dos nove anos/ A vida cheia de sonhos/ } \\
\text { Coletivo imaginário. } \\
\text { Além do mesmo colégio/ Moravam na mesma rua/ Amizade de } \\
\text { infância/ Pela vida continua/ Rita, Cristina e Odete/ Ana Lúcia e } \\
\text { Margarete/ Feito o canto da perua. }\end{array}$ \\
\hline $\begin{array}{l}\text { Complicação } \\
\text { Desencadeador (Pn2) }\end{array}$ & $\begin{array}{l}\text { No fim do primeiro grau/ Antes da adolescência/ A vida com seus } \\
\text { mistérios/ Seus segredos e cadência/ Mudou aquela rotina/ Mandando } \\
\text { cada menina/ Para nova residência. } \\
\text { Separaram-se assim/ Não houve nem despedida/ Cada família a seu } \\
\text { jeito/ Buscando melhores vidas/ Então naquele momento/ Houve este } \\
\text { rompimento/ As amizades partidas. }\end{array}$ \\
\hline $\begin{array}{l}\text { Situação } \\
\text { orientação }(\mathrm{Pn} 1)\end{array}$ & $\begin{array}{l}\text { O Brasil naquela época/ Mudou sua direção/ Uma nova economia/ } \\
\text { Regime de exceção/ Com rigor a ditadura/ Ganhou a contracultura/ E } \\
\text { perdeu a educação. } \\
\text { Vou dá um pulo no tempo/ Passando várias auroras/ Depois de } \\
\text { quarenta anos/ As meninas já senhoras/ Para descobrir de vez/ Tudo } \\
\text { o que a vida fez/ Como estão elas agora? }\end{array}$ \\
\hline $\begin{array}{l}\text { Ações ou avaliação } \\
\text { (Pn3) }\end{array}$ & $\begin{array}{l}\text { Primeiro a Ana Lúcia/ Foi para o Rio de Janeiro/ Com a vida } \\
\text { independente/ Não queria ter parceiro/ Menina, moça e madura/ } \\
\text { Estudou arquitetura/ Um talento pioneiro. } \\
\text { A família de Cristina/ Foi com ela pro nordeste/ Morar lá em } \\
\text { Pernambuco/ No interior agreste/ Por lá se casou bem cedo/ Sem } \\
\text { mistério sem segredo/ Teve três cabras da peste. } \\
\text { A Rita por sua vez/ Foi beber na mesma fonte/ Ficou em Minas Gerais/ } \\
\text { Em um novo horizonte/ Por questões familiares/ Foi conhecer novos } \\
\text { ares/ Ali em Belo Horizonte. } \\
\text { Margarete em São Paulo/ Muito a vida melhorou/ Uma grande } \\
\text { empresária/ No comércio caminhou/ Casarão no Morumbi/ Fazenda em } \\
\text { Jundiaí/ Férias no exterior. } \\
\text { O destino da Odete/ Foi com ela mais cruel/ Nas estradas do Brasil/ } \\
\text { Morava em praça e bordel/ Jovem sem teto e sem prisma/ Teve um } \\
\text { fatal aneurisma/E cedo pro céu subiu. } \\
\text { Depois de quarenta anos/ Resolveram se encontrar/ Por sugestão de } \\
\text { Cristina/ Que resolveu procurar/ Uma a uma descobriu/ E a turma } \\
\text { reuniu/ Pra tudo relembrar. }\end{array}$ \\
\hline
\end{tabular}




\begin{tabular}{|c|c|}
\hline $\begin{array}{l}\text { Resolução } \\
\text { Desencadeador (Pn4) }\end{array}$ & $\begin{array}{l}\text { No reencontro das quatro/ Foi a maior alegria/ Enorme felicidade/ } \\
\text { Ocorreu naquele dia/ Rebuscavam na memória/ Cada uma sua } \\
\text { história/ Lembravam em harmonia. } \\
\text { Uma falava dos filhos/ A outra do seu coração/ A Margarete falou/ Da } \\
\text { sua situação/ Mulher rica e desquitada/ No amor desamparada/ Mas } \\
\text { no resto agitação. }\end{array}$ \\
\hline $\begin{array}{l}\text { Situação inicial ou } \\
\text { orientação (Pn1) }\end{array}$ & $\begin{array}{l}\text { Elas ficariam juntas/ Todo o final de semana/ No grande hotel da } \\
\text { cidade/ Uma pousada bacana/ No domingo o almoço/ Seria um } \\
\text { alvoroço/ Na Fazenda Jaguarana. } \\
\text { Em um domingo de sol/ Na mesa muita fartura/ A comidinha mineira/ } \\
\text { Couve frita na gordura/ Feijão do tipo tropeiro/ Caprichado no } \\
\text { tempero/ Arroz, linguiça e verdura. } \\
\text { Também tinhas ovos fritos/ Porco, galinha e tutu/ Muita conversa } \\
\text { fiada/ Com polenta de angu/ No final a sobremesa/ Goiabada que } \\
\text { beleza/ Doce de leite e caju. } \\
\text { O tempo tava voando/ Como sempre ele faz/ Conserta, ajeita e ajusta/ } \\
\text { Nisto muito eficaz/ Estava chegando a hora/ Das quatro irem embora/ } \\
\text { Naquele dia de paz. }\end{array}$ \\
\hline $\begin{array}{l}\text { Complicação } \\
\text { Desencadeador (Pn2) }\end{array}$ & $\begin{array}{l}\text { Voltaram para a cidade/ Ana Lúcia dirigindo/ No mesmo que carro que } \\
\text { foram/ Um carro novo tinindo/ Mas o destino chegou/ Um caminhão } \\
\text { colocou/ Na contramão ele vindo. } \\
\text { Um acidente fatal/ Morreram as quatro ali/ O motorista exclamava:/ } \\
\text { Meu Deus, coisa assim nunca vi!/ Ficou atrás de socorro/ Gritando eu } \\
\text { quase que morro!/ No dia que nem bebi! }\end{array}$ \\
\hline $\begin{array}{l}\text { Ações ou avaliação } \\
\text { (Pn3) }\end{array}$ & $\begin{array}{l}\text { As quatro amigas subiram/ Nas nuvens se encontraram/ _ O que foi } \\
\text { que aconteceu?/ Elas ali perguntavam/ E nisso chegou alguém/ Vindo } \\
\text { de lá do além/ Quando as quatro conversavam. }\end{array}$ \\
\hline $\begin{array}{l}\text { Resolução } \\
\text { Desencadeador (Pn4) }\end{array}$ & $\begin{array}{l}\text { Foi a Odete chegando/ Que já tinha então morrido/ Foi dizendo: } \\
\text { Pessoal!/ Sem pressa e sem alarido/ Lutei com fé e afinco/ Para } \\
\text { juntarmos nós cinco/ Num lugar despoluído. } \\
\text { Aqui é bom de verdade/ Estamos perto de Deus/ As agonias de terra/ } \\
\text { Desencantos, fariseus/ Pilantragem, covardia/ Ocorrendo dia a dia/ } \\
\text { Desgastes demais, adeus. } \\
\text { A Rita Ihe perguntou:/ _ Como você conseguiu?/ _ Enquanto eu estava } \\
\text { viva/ A Odete prosseguiu:/ _ Pensava neste roteiro/ Mas como subi } \\
\text { primeiro/ Nunca o encontro existiu. } \\
\text { Então eu fiquei matutando/ Esperando este momento/ Encontrar-me } \\
\text { com vocês/ Era o meu pensamento/ Encostei no motorista/ Tirando ele } \\
\text { da pista/ Deixando-o desatento. }\end{array}$ \\
\hline Situação final (Pn5) & $\begin{array}{l}\text { Depois daquele encontro/ O grupo então mais sereno/ Refletindo sobre } \\
\text { o fato/ Num instante mais ameno/ Uniram-se num só véu/ Subiram } \\
\text { todas pro céu/ Sem sequer fazer aceno. }\end{array}$ \\
\hline Moral $(\mathrm{Pn} \Omega)$ & $\begin{array}{l}\text { A conclusão que cheguei/ Sobre a morte repentina/ Tem lá o seu lado } \\
\text { bom/ O lado que nos ensina/ Não é uma permissão/ A vida é uma } \\
\text { missão/ Naquilo que se destina. }\end{array}$ \\
\hline
\end{tabular}

Fonte: Autoras. 
No cordel As minas de Minas, identificamos a sequência narrativa com todas as macroproposições propostas por Adam (1992), embora nem sempre apareçam na ordem estabelecida pelo autor. Verificamos que a organização textual do cordel é sustentada por um processo de intriga, com início, meio e fim. No texto as macroproposições aparecem sob a forma de (Pn1) situação inicial, (Pn2) complicação, (Pn3) ações ou avaliação, (Pn4) resolução, (Pn5) situação final e $(\mathrm{Pn} \Omega)$ moral.

As ocorrências de macroproposições narrativas identificadas no cordel se apresentam da seguinte forma:

- Pn1 - 3 ocorrências;

- Pn2 - 2 ocorrências;

- Pn3- 2 ocorrências;

- Pn4- 2 ocorrências;

- Pn5 - 1 ocorrência;

- $\mathrm{Pn} \Omega-1$ ocorrência.

A Pn1 (situação inicial) aparece no início do texto para apresentar as personagens Rita, Cristina, Odete, Ana Lúcia e Margarete, bem como o lugar e o tempo em que essa história acontece. Posteriormente, aparece para inserir uma situação nova com as personagens. Essas situações de equilíbrio contribuem para impulsionar Pn2 (complicação), responsável por criar uma tensão, que desencadeia uma mudança na vida dessas amigas. Nesse momento as personagens vivenciaram situações Pn3 (ações) originadas por essa tensão. A Pn4 (resolução) é responsável por introduzir os acontecimentos que irão reduzir a tensão criada. Neste momento que ocorre o acerto entre as amigas após ficarem separadas por quarenta anos. Já a Pn5 (situação final) aparece somente no final do texto para apresentar um novo estado de equilíbrio, alcançado na fase de resolução da tensão, no acerto entre as personagens. Por fim, temos a $\mathrm{Pn} \Omega$ (moral), fase em que há uma reflexão explícita sobre o fato narrado.

Dessa forma, as sequências narrativas contribuem para dar forma ao cordel, e todas as suas macroproposições são usadas na constituição das personagens e no desenvolvimento da narrativa. 


\section{Considerações Finais}

Apresentamos uma análise da realização da sequência narrativa no cordel 'As minas de Minas', de Chico Salles (2008). A fim de verificarmos o protótipo narrativo nesse texto, baseamo-nos nas teorias de Adam e de Bronckart acerca da sequencialidade textual. De modo a desenvolvermos este estudo, estabelecemos como objetivo verificar o encadeamento e a função da sequência narrativa no texto selecionado. Inicialmente, efetuamos uma reflexão sobre as sequências prototípicas, em seguida, apresentamos o protótipo narrativo e por fim, analisamos seu encadeamento e função no texto.

Em nossa análise verificamos que a organização textual do cordel é sustentada por um processo de intriga, com início, meio e fim, mas não aparecem na ordem estabelecida pelo autor. Assim, identificamos as seguintes ocorrências de macroproposições narrativas no cordel: Pn1 (situação inicial) - 3 ocorrências; Pn2 (complicação) - 2 ocorrências; Pn3 (ações) - 2 ocorrências; Pn4 (resolução) - 2 ocorrências; Pn5 (situação final) - 1 ocorrência; $\operatorname{Pn} \Omega$ (moral) - 1 ocorrência.

No que diz respeito à função da sequência narrativa presente no cordel de Chico Salles, observamos que esta é fundamental para a organização textual e, consequentemente, para constituição das personagens e desenvolvimento da narrativa. Assim, ao identificarmos e analisarmos a sequência narrativa, constatamos que o texto apresentou todas as macroproposições necessárias para o desenvolvimento da trama, conforme as perspectivas teóricas abordadas. 0 protótipo narrativo tem um papel fundamental no texto, sendo responsável pelas relações de sentido e pela unidade textual, bem como pela forma que são apresentadas as intenções do autor e como o leitor pode interpretá-las. 


\section{Referências}

ADAM, Jean-Michel. $A$ linguística textual: introdução à análise textual dos discursos. São Paulo: Cortez, 2011.

ADAM, Jean-Michel. Cadre théorique d'une typologie séquentielle. Études de Linguistique Appliquée: textes, discours types et genres. n. 83. p. 6-18, 1991.

ADAM, Jean-Michel. Les textes. types et prototypes. Paris: Natham, 1992.

BRONCKART, Jean-Paul. Atividade de linguagem, textos e discursos. por um interacionismo sóciodiscursivo. Tradução de Anna Raquel Macchado e Péricles Cunha. São Paulo: EDUC, 2003.

LABOV, William; WALETZKY, Joshua. Narrative analysis: oral versions of personal experience. In: HELM, June (ed.). Essays onthe verbal and visual arts. Seattle: University of Washington Press, 1967. p. 12-44.

MACHADO, Anna Rachel. A organização sequencial da resenha crítica. The Especialist, São Paulo, v. 17, n. 2, p. 133-149, 1996.

SALLES, Chico. As Minas de Minas. João Pessoa, PB: Editora Rovelle: Paraíba JC Livros, 2008.

SILVA, Aurenívia Ferreira. Um estudo da realização da sequência narrativa no gênero notícia. 2007. Dissertação (Mestrado em Linguística) - Universidade Federal do Ceará, Fortaleza, 2007. Disponível em: http://www.repositorio.ufc.br/bitstream/riufc/3617/1/2007_dis_afsilva.pdf. Acesso em: 15 jul. 2018. 